\title{
PENGARUH FAKTOR KUALITAS PELAYANAN BIRO PERJALANAN WISATA TERHADAP KEPUASAN WISATAWAN PADA PAKET WISATA BULAN MADU KE BALI
}

\author{
Dwi Widya Mandasari \\ I Ketut Suwena \\ I Wayan Suardana \\ Email : mandasari@yahoo.com \\ PS. S1 Industri Perjalanan Wisata \\ Fakultas Pariwisata UNUD
}

\begin{abstract}
ABSTRAK
Fokus dari penelitian ini adalah pengaruh faktor kualitas pelayanan biro perjalanan wisata terhadap kepuasan wisatawan pada paket wisata bulan madu ke Bali. Tujuan penelitian ini adalah untuk mengetahui: (1) faktor yang menjadi penentu dari kualitas pelayanan pada paket wisata bulan madu ke Bali, (2) faktor yang dominan dalam kualitas pelayanan pada paket wisata bulan madu ke Bali, dan (3) pengaruh kualitas pelayanan terhadap kepuasan wisatawan pada paket wisata bulan madu ke Bali. Lokasi penelitian dilakukan di tempat wisata Ubud, Pantai Jimbaran, Kintamani, dan Bedugul. Dari tempat tersebut, dijumpai biro perjalanan wisata yang sedang menyelenggarakan paket wisata bulan madu ke Bali, antara lain Hana Tour and Travel, Bali Suci Tour and Travel, Korean Travel, My Bali Tour serta Triangle Tour and Travel. Teknik penentuan sampel menggunakan Slovin dengan mengambil 100 wisatawan yang sedang menggunakan paket wisata bulan madu ke Bali, dan teknik yang digunakan Judgment Sampling. Wisatawan yang menggunakan paket wisata bulan madu 55\% berasal dari Indonesia dan $45 \%$ berasal dari mancanegara.. Teknik analisis data menggunakan analisis kualitatif dan kuantitatif. Analisis kuantitatif digunakan pada analisis faktor dan regresi sederhana. Hasil analisis faktor menunjukkan bahwa lima (5) variabel kualitas pelayanan TERRA dari Parasuraman (1985) antara lain Tangible/bukti langsung, Empathy/empati, Reliability/keandalan, Responsive/daya tanggap, Assurance/jaminan, merupakan faktor dari kualitas pelayanan pada paket wisata bulan madu ke Bali. Nilai eigen value dari faktor Tangible/bukti langsung $=2.694$, Empathy/empati dengan eigen value $=$ 2.254, Reliability/keandalan dengan eigen value $=1.991$, Responsive/daya tanggap dengan eigen value $=3.107$, dan Assurance/jaminan dengan eigen value $=4.176$. Faktor yang dominan dalam kualitas pelayanan pada paket wisata bulan madu ke Bali adalah faktor jaminan/assurance. Hasil dari uji regresi sederhana di dapat nilai $\mathrm{R}$ square sebesar 0,64. Ini berarti pengaruh variabel kualitas pelayanan terhadap kepuasan wisatawan sebesar $64 \%$. Sedangkan sisanya sebesar $36 \%$ dipengaruhi oleh variabel lain yang tidak masuk dalam model penelitian. Diharapkan bagi biro perjalanan wisata yang menjual paket wisata bulan madu ke Bali dapat lebih memperhatikan faktor jaminan/assurance. Karena faktor jaminan merupakan faktor penentu dari kepuasan wisatawan yang menggunakan paket wisata bulan madu ke Bali.
\end{abstract}

Kata Kunci: Paket Wisata Bulan Madu, Faktor Kualitas Pelayanan, Kepuasan Wisatawan.

\section{PENDAHULUAN}

Adanya persaingan pasar yang sangat ketat membuat Biro Perjalanan Wisata (BPW) di Bali berlomba untuk memenuhi kebutuhan dan kepuasan wisatawan. Paket wisata bulan madu ke Bali salah satu pilihan untuk wisatawan yang tidak pernah sepi dari peminat, membuat BPW semakin inovatif dalam mengemas paket wisata tanpa mengenyampingkan kualitas pelayanan yang diberikan demi kepuasan wisatawan. Paket 
wisata bulan madu ini merupakan paket wisata khusus dan tidak semua BPW bisa menyelenggarakan paket wisata ini. Salah satu contoh paket wisata bulan madu ke Bali oleh Biro Perjalanan Wisata My Bali Tour yaitu paket 4 hari 3 malam antara lain; Hari 1 Tiba di Pulau Dewata Bali - Photo Adat Bali. Hari 2 Tanjung Benoa Wisata Air - Spa Treatment Dinner Cruise. Hari 3 Fullday Bedugul - Tanah Lot. Hari 4 Hotel - Transfer Airport. (Sumber, www.mybalitour.com)

Perhatian khusus diperlukan dalam menyelenggarakan paket wisata bulan madu ini. Oleh karena itu, penulis tertarik untuk meneliti faktor yang menentukan kepuasan wisatawan pada paket wisata bulan madu ke Bali, khususnya kepuasan wisatawan terhadap pelayanan yang diberikan oleh biro perjalanan wisata. Biro Perjalanan Wisata merupakan perantara dari wisatawan untuk menyediakan produk wisata lainnya. Rumusan masalah dari penelitian ini adalah: (1) Faktor - faktor apa saja yang menjadi penentu dari kualitas pelayanan pada paket wisata bulan madu ke Bali, (2) Faktor pelayanan manakah yang dominan dalam menentukan kualitas pelayanan pada paket wisata bulan madu ke Bali, (3) Bagaimana pengaruh kualitas pelayanan terhadap kepuasan wisatawan pada paket wisata bulan madu ke Bali.

\section{METODE PENELITIAN}

Penelitian ini dilakukan di kawasan wisata Ubud, Kintamani, dan Bedugul. Dari tempat tersebut dijumpai biro perjalanan wisata yang sedang menyelenggarakan paket wisata bulan madu ke Bali, antara lain Hana Tour and Travel, Bali Suci Tour and Travel, Korean Travel, dan My Bali Tour. Teknik penentuan sampel menggunakan Slovin dengan mengambil 100 wisatawan, dan teknik yang digunakan Judgment Sampling. Wisatawan yang menggunakan paket wisata bulan madu 55\% berasal dari Indonesia dan $45 \%$ berasal dari mancanegara. Teknik analisis data menggunakan analisis kualitatif dan kuantitatif. Kuantitatif digunakan pada analisis faktor dan regresi sederhana

HASIL DAN PEMBAHASAN Karakteristik Responden
Berdasarkan penyebaran kuesioner dengan jumlah 100 orang wisatawan yang menggunakan paket wisata bulan madu ke Bali, Tour and ratarata wisatawan berasal berasal dari Indonesia sebanyak 55\%, dan 45\% lainnya berasal dari mancanegara. Sebanyak 22\% wisatawan menggunakan Hana Tour and Travel, 44\% wisatawan menggunakan Bali Suci Travel, Korean Travel 24\% dan My Bali 20\% wisatawan.

\section{Analisis Faktor}

Pada hasil analisis pengujian instrumen penelitian yang merupakan syarat untuk mengetahui layak tidaknya instrumen yang digunakan, dapat diketahui dari 16 indikator untuk variabel independen yaitu faktor kualitas pelayanan $(\mathrm{X})$ dan 5 indikator untuk variabel dependen yaitu kepuasan wisatawan (Y) dinyatakan valid dan reliabel karena koefisien korelasi dan cronbach alpha telah memenuhi syarat pengujian, dimana melebihi 0,3 untuk pengujian validitas atau dengan kata lain dapat diukur dan tahap berikutnya didapatkan hasil melebihi 0,6 untuk pengujian realibilitas atau alat ukur yang digunakan menunjukkan konsistensi, sehingga dapat disimpulkan bahwa instrumen atau alat ukur yang digunakan yaitu variabel faktor kualitas pelayanan (X) dan kepuasan wisatawan (Y) telah memenuhi semua kriteria pengujian untuk kemudian dilanjutkan dalam analisis faktor.

Analisis faktor dilakukan untuk mengetahui faktor kualitas pelayanan yang paling mempengaruhi kepuasan wisatawan pada paket wisata bulan madu ke Bali. Dari permasalah ini diketahui 16 indikator dari 5 faktor kualitas pelayanan yang mempengaruhi kepuasan wisatawan yaitu:

a. Faktor Jaminan/Assurance

Faktor jaminan/assurance termasuk faktor kualitas pelayanan yang menentukan kepuasan wisatawan pada paket wisata bulan madu ke Bali (dengan eigen value $=4.176$ ). Indikator yang tercakup pada faktor ini terdiri dari 4 indiktor, yaitu: 


\section{Tabel 1}

Faktor Jaminan/Asssurance

\begin{tabular}{|l|l|}
\hline No. & \multicolumn{1}{|c|}{ Indikator } \\
\hline 1. & Karyawan yang sopan (X12) \\
\hline 2. & $\begin{array}{l}\text { Kayawan yang memilikipengetahuan untuk } \\
\text { menjawab pertanyaan (X13) }\end{array}$ \\
\hline 3. & $\begin{array}{l}\text { Membuat wisatawan merasa nyaman untuk } \\
\text { melakukan transaksi (X11) }\end{array}$ \\
\hline 4. & $\begin{array}{l}\text { Karyawan yang menanamkan rasa percaya } \\
\text { diri kepada pelanggan (X10) }\end{array}$ \\
\hline
\end{tabular}

b. Faktor Daya Tanggap/Responsive

Faktor daya tanggap/responsive termasuk faktor kualitas pelayanan yang menentukan kepuasan wisatawan pada paket wisata bulan madu ke Bali (eigen value = 3.107).indikator yang tercakup pada faktor ini antara lain :

Tabel 2

Faktor Daya Tanggap/Responsive

\begin{tabular}{|l|l|}
\hline No. & \multicolumn{1}{|c|}{ Indikator } \\
\hline 1. & $\begin{array}{l}\text { Menanggapi keluhan wisatawan dengan cepat } \\
\text { (X9) }\end{array}$ \\
\hline 2. & $\begin{array}{l}\text { Memberikan informasi yang relevan untuk } \\
\text { memecahkan masalah (X8) }\end{array}$ \\
\hline 3. & Tersedia bantuan ketika terjadi masalah (X7) \\
\hline
\end{tabular}

c. Faktor Bukti Langsung/Tangible

Faktor bukti langsung/tangible termasuk faktor kualitas pelayanan yang menentukan kepuasan wisatawan pada paket wisata bulan madu ke Bali (eigen value $=2.694$ ). Indikator yang tercakup didalamnya adalah:

Tabel 3

Faktor Bukti Langsung/Tangible

\begin{tabular}{|l|l|}
\hline No. & \multicolumn{1}{|c|}{ Indikator } \\
\hline 1. & Kelengkapan fasilitas hotel yang ditawarkan $(\mathrm{X} 3)$ \\
\hline 2. & Interior bangunan hotel yang menarik $(\mathrm{X} 1)$ \\
\hline 3. & Kebersihan tempat wisata $(\mathrm{X} 2)$ \\
\hline d. & Faktor Empati/Empathy \\
& Faktor empati/empathy merupakan faktor \\
& kualitas pelayanan yang menentukan \\
& kepuasan wisatawan pada paket wisata bulan \\
& madu ke Bali (eigen value = 2.254) indikator \\
& yang termasuk di dalamnya adalah:
\end{tabular}

Tabel 4

Faktor Empati/Empathy

\begin{tabular}{|l|l|l|}
\hline No. & \multicolumn{1}{|c|}{ Indikator } \\
\hline 1. & Tersedia layanan 24 jam (X14) \\
\hline 2. & $\begin{array}{l}\text { Karyawan mengetahui keinginan pelanggan } \\
(X 15)\end{array}$ \\
\hline
\end{tabular}

\begin{tabular}{|l|l|}
\hline 3. & Karyawan mampu berkomunikasi dengan baik \\
\hline
\end{tabular} (X16)

e. Faktor Keandalan/Reliability

Faktor keandalan/reliability adalah faktor kualitas pelayanan yang menentukan kepuasan wisatawan pada paket wisata bulan madu ke Bali (eigen value = 1.991). indikator yang termasuk didalamnya adalah :

Tabel 5

Faktor Keandalan/Reliability

\begin{tabular}{|l|l|}
\hline No. & \multicolumn{1}{|c|}{ Indikator } \\
\hline 1. & Memberikan layanan yang benar sejak awal (X6) \\
\hline 2. & $\begin{array}{l}\text { Kemampuan karyawan menangani masalah } \\
\text { dengan baik (X5) }\end{array}$ \\
\hline 3. & $\begin{array}{l}\text { Memberikan pelayanan seperti yang telah } \\
\text { dijanjikan (X4) }\end{array}$ \\
\hline
\end{tabular}

Berdasarkan penjelasan di atas faktor jaminan/assurance merupakan faktor terpenting dalam kualitas pelayanan yang memberikan pengaruh besar terhadap kepuasan wisatawan pada paket wisata bulan madu ke Bali, dengan eigen value 4,176.

Berdasarkan hasil wawancara, sebagian besar wisatawan menyatakan puas dengan pelayanan yang diberikan, terutama dengan faktor jaminan/assurance. Biro perjalanan wisata yang menjual paket wisata bulan madu ke Bali memberikan perhatian dengan cara menghubungi wisatawan yang sedang menggunakan paket wisata bulan madu, dan menanyakan pelayanan apa yang dirasa kurang agar wisatawan merasa puas dengan pelayanan dari biro perjalanan yang menjual paket wisata bulan madu ke Bali. Untuk dapat memberikan rasa percaya wisatawan terhadap transaksi pembayaran yang dilakukan, bisa dilakukan pembayaran $50 \%$ terlebih dahulu, selebihnya bisa dilunasi di tempat.

Penelitian ini sejalan dengan penelitian Clemes (2008) dengan hasil faktor jaminan/assurance merupakan faktor terpenting dalam meningkatkan kepuasan wisatawan dalam dunia penerbangan Internasional di New Zealand.

\section{Regresi Sederhana}

Untuk mengetahui pengaruh kualitas pelayanan biro perjalanan wisata terhadap kepuasan wisatawan pada paket wisata bulan madu ke Bali, dilakukan uji regresi. Hasil dari 
uji regresi sederhana di dapat nilai $\mathrm{R}$ square pada analisis regresi sedehana adalah sebesar 0,64. Ini berarti pengaruh variabel kualitas pelayanan terhadap kepuasan wisatawan sebesar $64 \%$. Sedangkan sisanya sebesar $36 \%$ dipengaruhi oleh variabel lain yang tidak masuk dalam model penelitian.

Adapun persamaan regresi yang dapat dilihat dari hasil analisis regresi berganda, yaitu $\mathrm{Y}=3,582+0,123(\mathrm{X})$.

Berdasarkan hasil analisis regresi berganda dan uji F yang telah dilakukan, dapat dinyatakan bahwa kualitas pelayanan (X) berpengaruh secara simultan terhadap kepuasan wisatawan (Y).

Berdasarkan persamaan tersebut, maka variabel kualitas pelayanan berpengaruh terhadap kepuasan wisatawan pada paket wisata bulan madu ke Bali. Diketahui konstanta besarnya 3,582 mengandung arti jika variabel kualitas pelayanan tidak berubah, maka kualitas pelayanan $(\mathrm{Y})$ tidak mengalami perubahan atau sama dengan 3,582.

Untuk melihat pengaruh variabel kualitas pelayanan terhadap variabel kepuasan wisatawan secara parsial maka dilakukan uji hipotesis yaitu uji-t. Hasil uji t menunjukan bahwa kualitas pelayanan terbukti berpengaruh positif signifikan secara parsial terhadap kepuasan wisatawan (Y) karena telah memenuhi syarat penerimaan hipotesis yaitu $t$ hitung lebih besar dibandingkan $\mathrm{t}$ tabel, dengan $\mathrm{t}$ hitung sebesar 2,581 dan $t$ tabel 1,660.

\section{SIMPULAN DAN SARAN}

Berdasarkan analisis data dan pembahasan yang telah dilakukan dapat disimpulkan sebagai berikut:

1. Terdapat 5 faktor kualitas pelayanan yang menjadi penentu dalam kepuasan wisatawan pada paket wisata bulan madu ke Bali yaitu:

(1) Tangible/bukti langsung dengan nilai eigen value $=2.694$, (2) Empathy/empati dengan eigen value $=2.254$, (3) Reliability/keandalan dengan eigen value $=$ 1.991, (4) Responsive/daya tanggap dengan eigen value $=3.107$, dan (5) Assuranceljaminan dengan eigen value = 4.176

2. Dari 5 faktor kualitas pelayanan, faktor yang dominan dalam menentukan kepuasan wisatawan pada paket wisata bulan madu ke Bali yaitu faktor jaminan/assurance dengan eigen value 4,176.

3. Berdasarkan hasil analisis regresi berganda dan uji $\mathrm{F}$ yang telah dilakukan, dapat dinyatakan bahwa faktor kualitas pelayanan (X) berpengaruh secara simultan terhadap kepuasan wisatawan (Y). Adapun persamaan regresi yang dapat dilihat dari hasil analisis regresi berganda, yaitu $\mathrm{Y}=$ $3,582+0,123(\mathrm{X})$. Diketahui konstanta besarnya 3,582 mengandung arti jika variabel kualitas pelayanan tidak berubah, maka kualitas pelayanan (Y) tidak mengalami perubahan atau sama dengan 3,582. Dari hasil uji t menunjukan bahwa kualitas pelayanan terbukti berpengaruh positif signifikan secara parsial terhadap kepuasan wisatawan (Y) karena telah memenuhi syarat penerimaan hipotesis yaitu $t$ hitung lebih besar dibandingkan $t$ tabel, dengan $\mathrm{t}$ hitung sebesar 2,581 dan $\mathrm{t}$ tabel 1,660. Hasil dari uji regresi sederhana di dapat nilai $\mathrm{R}$ square sebesar 0,64 . Ini berarti pengaruh variabel kualitas pelayanan terhadap kepuasan wisatawan sebesar $64 \%$. Sedangkan sisanya sebesar $36 \%$ dipengaruhi oleh variabel lain yang tidak masuk dalam model penelitian

Selanjutnya, Berdasarkan pembahasan yang telah dijelaskan sebelumnya maka saran yang dapat diberikan kepada biro perjalanan wisata yang menjual paket wisata bulan madu ke Bali diharapkan agar dapat lebih memperhatikan faktor jaminan/assurance untuk dapat memberikan kepuasan untuk wisatawan.

\section{DAFTAR PUSTAKA}

Clemes, M., Dkk. 2008. An empirical analysis of customer satisfaction in international air Travel. Innovative Marketing, Volume 4, Issue 2, 2008. Diakses Pada 23 Januari 2015 Pukul 16.00 WITA.

Hardiyati, R. 2010. Analisis Pengaruh Kualitas Pelayanan Terhadap Kepuasan Konsumen Menggunakan Jasa Penginapan (Villa) Agrowisata Kebun Teh Pagilaran. Skipsi Fakultas Ekonomi Universitas Diponegoro. Semarang. 
Vol. 4 No. 1, 2016

Tomar, S., dkk. 2013. Measuring Foreign Traveler's Satisfaction with Traveling Agencies in India. IOSR Journal of Business and Management (IOSR-JBM) e-ISSN: 2278-487X, p-ISSN: 2319-7668. Volume 12, Issue 1 (Jul. - Aug. 2013), PP 26-32 www.iosrjournals.org. Diakses Pada 22 Januari 2015, Pukul 17.30 WITA

Suwintari, I Gusti Eka. 2012. Kepuasan Wisatawan Terhadap Kualitas Pelayanan "Tourist Information Counters" di Jalan Padma Utara Legian, Kuta. Thesis Program Pascasarjanah Universitas Udayana. Denpasar.

Tjiptono, F. 2001. Manajemen Jasa, Edisi Kedua. Yogyakarta: Andi Offset.

Zeith, Parasuraman and Berry. 1985. Problem and Strategies in Service Marketing. Journal Of Marketing. Diakses Pada Tanggal 24 Januari 2015, Pukul 20.30 WITA.

www.mybalitour.com. Diakses Pada Tanggal 21

Oktober 2015, Pukul 12.00 Wita 